\title{
PHOSPHORUS REGULATION IN CHRONIC KIDNEY DISEASE
}

\author{
Wadi N. Suki, M.D.; Linda W. Moore, M.S., R.D.N. \\ Houston Methodist Hospital, Houston, Texas
}

\begin{abstract}
Serum phosphorus levels stay relatively constant through the influence of multiple factors - such as parathyroid hormone, fibroblast growth factor 23, and vitamin D-on the kidney, bone, and digestive system. Whereas normal serum phosphorus ranges between $3 \mathrm{mg} / \mathrm{dL}$ to $4.5 \mathrm{mg} / \mathrm{dL}$, large cross-sectional studies have shown that even people with normal kidney function are sometimes found to have levels ranging between $1.6 \mathrm{mg} / \mathrm{dL}$ and $6.2 \mathrm{mg} / \mathrm{dL}$. While this may partially be due to diet and the factors mentioned above, total understanding of these atypical ranges of serum phosphorus remains uncertain. Risks for bone disease are high in people aged 50 and older, and this group comprises a large proportion of people who also have chronic kidney disease. Consuming diets low in calcium and high in phosphorus, especially foods with phosphate additives, further exacerbates bone turnover. Existing bone disease increases the risk for high serum phosphorus, and higher serum phosphorus has been associated with increased adverse events and cardiovascular-related mortality both in people with chronic kidney disease and in those with no evidence of disease. Once kidney function has deteriorated to end-stage disease (Stage 5), maintaining normal serum phosphorus requires dietary restrictions, phosphate-binding medications, and dialysis. Even so, normal serum phosphorus remains elusive in many patients with Stage 5 kidney disease, and researchers are testing novel targets that may inhibit intestinal transport of phosphorus to achieve better phosphate control. Protecting and monitoring bone health should also aid in controlling serum phosphorus as kidney disease advances.
\end{abstract}

\section{Introduction}

In large cross-sectional population studies, mean serum phosphorus (or inorganic phosphate, iP) remains fairly constant at approximately $3.8 \mathrm{mg} / \mathrm{dL}$ in subjects with normal kidney function. It does the same in those with impaired kidney function until the glomerular filtration rate (GFR) falls to below $30 \mathrm{~mL} / \mathrm{min} / 1.73$ $\mathrm{m}^{2}$-which represents Stage 4 chronic kidney disease (CKD). At this point serum phosphorus levels start to rise and continue rising as these patients reach end-stage kidney disease (ESRD, Stage 5). ${ }^{1}$ The relative constancy of the serum iP in normal and early kidney disease is maintained by the interaction of multiple factors including parathyroid hormone (PTH), fibroblast growth factor 23 (FGF 23), vitamin $D$, and others acting on the gut, kidneys, and bone.

\section{Serum Phosphorus Range, Function, and Consequence}

For clinical purposes, the normal range of serum iP is said to be between $3 \mathrm{mg} / \mathrm{dL}$ and $4.5 \mathrm{mg} / \mathrm{dL}$. However, in large cross-sectional studies of normal subjects, and in subjects with mild or moderate renal function impairment, serum iP has been reported to range between $1.6 \mathrm{mg} / \mathrm{dL}$ and $6.2 \mathrm{mg} / \mathrm{dL}{ }^{1-3}$ The reasons for this wide range of serum iP appear to be due in part to diet, $\mathrm{PTH}$, and vitamin D level but mostly due to factors yet to be identified. Of note, examination of U.S. adults between 1988 and 1994 revealed a mean serum phosphorus of $3.4 \mathrm{mg} / \mathrm{dL}$, but more recent data (2003-2006) demonstrates the mean to be $3.8 \mathrm{mg} / \mathrm{dL} .{ }^{1,4}$ The reason for this increase remains uncertain.

Present mainly within cells, phosphorus is critical for multiple biological and biochemical reactions vital to the maintenance of life, not the least of which is storage of energy to be used by all cells including skeletal and heart muscle. Severe deficiency of phosphorus results in multiple systemic disorders, as would be anticipated. However, a number of recent studies have demonstrated a correlation between the level of serum iP and the development of cardiovascular and cerebrovascular events, with higher levels of serum iP-within the expanded "normal" range-predicting a higher risk of adverse events. ${ }^{5,6}$ In patients with ESRD, in whom all-cause mortality and cardiovascular mortality are markedly higher than in subjects with normal renal function, and in those with mild or moderate renal function impairment, a serum iP level greater than $5.5 \mathrm{mg} / \mathrm{dL}$ is associated with a further increase in the risk of cardiovascular and all-cause mortality. These observations have prompted clinicians to focus on lowering serum iP as the primary strategy for managing dialysis patients. In accomplishing the goal, consideration should also be given to the events preceding ESRD that impede control of serum iP.

\section{Bone Disease Prevalence and Contribution to Serum Phosphorus}

As with the general population, people with CKD have baseline risks for bone disease that increase with loss of kidney function. Generally speaking, since bone is a contributor to phosphorus homeostasis, the prevalence of bone disease in U.S. adults should be taken into account when considering patients with CKD. More than 10 million U.S. adults over age 50 have osteoporosis, a preventable bone disease. ${ }^{7}$ Furthermore, it is estimated that more than 33.6 million adults over age 50 have reduced bone mass. ${ }^{8}$ Recent reports indicate that approximately $14 \%$ of U.S. adults have CKD, and $33 \%$ of U.S. adults aged 60 and older have CKD, approximately 15 million people. ${ }^{9}$ Therefore, a majority of these patients will have osteopenia or osteoporosis in addition to the mineral-bone disorder of CKD.

Bone health is dependent on dietary intake of vitamins and minerals (Table 1). Three major bone nutrients are calcium, phosphorus, and vitamin D. During growth and development, only one-fourth to one-third of dietary calcium is absorbed and almost entirely stored in bones and teeth. In contrast, approximately 70\% of dietary phosphorus is absorbed, and the amount of absorption depends on the type of phosphorus: $30 \%$ to $70 \%$ of the phospho- 


\begin{tabular}{|c|c|c|}
\hline Nutrients & Normal, Healthy Adults ${ }^{16}$ & Reduced Kidney Function ${ }^{17}$ \\
\hline Calcium & $\begin{array}{l}\text { Maintain adequate dietary calcium intake } \\
\text { RDA: } 1,000 \mathrm{mg} / \mathrm{d} \text { or } 1,200 \mathrm{mg} / \mathrm{d} \text { if }>70 \text { years of age } \\
\text { UL: } 2,500 \mathrm{mg} / \mathrm{d} \text { or } 2,000 \mathrm{mg} / \mathrm{d} \text { if }>70 \text { years of age }\end{array}$ & $\begin{array}{l}\text { Same as for normal, healthy adults } \\
\text { UL: } 2000 \mathrm{mg} / \mathrm{d}\end{array}$ \\
\hline Phosphorus & $\begin{array}{l}\text { Avoid excessive dietary phosphorus intake } \\
\text { RDA: } 700 \mathrm{mg} / \mathrm{d} \\
\text { UL: } 3,000 \mathrm{mg} / \mathrm{d}\end{array}$ & $\begin{array}{l}\text { CKD Stage } 3 \text { to } 5 \text {, same as for normal, healthy adults } \\
\text { UL: } 1,000 \mathrm{mg} / \mathrm{d}\end{array}$ \\
\hline Vitamin D & $\begin{array}{l}\text { RDA: } 15 \mu \mathrm{g} / \mathrm{d}(600 \mathrm{IU}) \text { or } 20 \mu \mathrm{g} / \mathrm{d}(800 \mathrm{IU}) \text { if }>70 \text { years of age } \\
\text { UL: } 100 \mu \mathrm{g} / \mathrm{d}(4,000 \mathrm{IU})\end{array}$ & No specific recommendation \\
\hline Magnesium & $\begin{array}{l}\text { RDA men: } 420 \mathrm{mg} / \mathrm{d} \\
\text { RDA women: } 320 \mathrm{mg} / \mathrm{d} \\
\text { UL: } 350 \mathrm{mg} / \mathrm{d}\end{array}$ & No specific recommendation \\
\hline Potassium & Al: $4,700 \mathrm{mg} / \mathrm{d}$ & $\begin{array}{l}<2,400 \mathrm{mg} / \mathrm{d} \text {, including kidney transplant recipients } \\
\text { (if hyperkalemia is present) }^{18}\end{array}$ \\
\hline Sodium & $\mathrm{Al}: 2,300 \mathrm{mg} / \mathrm{d}$ & $<2,400 \mathrm{mg} / \mathrm{d}$, including kidney transplant recipients ${ }^{18}$ \\
\hline Niacin & $\begin{array}{l}\text { RDA men: } 16 \mathrm{mg} / \mathrm{d} \\
\text { RDA women: } 14 \mathrm{mg} / \mathrm{d} \\
\text { UL: } 35 \mathrm{mg} / \mathrm{d}\end{array}$ & No specific recommendation \\
\hline
\end{tabular}

Table 1. Dietary recommendations for maintaining bone homeostasis in adults with and without kidney disease.

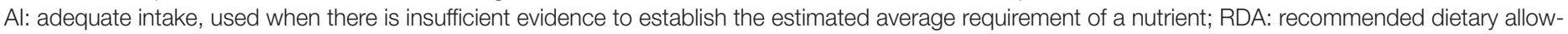
ance, the average daily intake of a nutrient sufficient to meet the needs of $97 \%$ to $98 \%$ of healthy individuals in a group; UL: tolerable upper intake level.

rus found naturally in foods is absorbable, ${ }^{10}$ whereas $100 \%$ of phosphorus from inorganic phosphate additives (used for preservation or enhancement of shelved foods and some baked goods) is absorbable. ${ }^{11}$ Furthermore, up to $23 \%$ of foods consumed in the United States have added inorganic phosphates. ${ }^{1}$ It is estimated that U.S. adults consume $180 \%$ of the recommended amount of dietary phosphorus without accounting for phosphate additives. Conversely, fewer than $10 \%$ of U.S. females aged 13 years and older meet the recommended amount of dietary calcium from foods, and even with dietary supplements, fewer than half of men aged 50 and older get an adequate amount of calcium..$^{12}$ In addition, dietary vitamin $\mathrm{D}$ intake is inadequate in the majority of adults even when accounting for dietary supplement use. ${ }^{12}$ This is important for bone health as well as cardiovascular and kidney health because biomarkers of bone turnover (e.g., serum parathyroid hormone, urine excretion of $\mathrm{N}$-terminal telopeptide of type 1 collagen) are increased and biomarkers of bone formation (e.g., bone-specific alkaline phosphatase) are decreased when dietary phosphorus intake is proportionally higher than dietary calcium intake. ${ }^{13-15}$ Increased bone turnover releases calcium and phosphorus into the circulation, leading to vascular medial calcinosis and a compensatory increase in parathyroid hormone and the phosphaturic hormone FGF23 to handle the increased phosphorus load. Ultimately, bones are potentially weakened and excess calcium is deposited into soft tissues because dietary nutrient intakes are inadequate (e.g., $<1000 \mathrm{mg} / \mathrm{d}$ of calcium) or excessive (e.g., $>700 \mathrm{mg} / \mathrm{d}$ of phosphorus). As kidney disease progresses and there is less ability to balance phosphorus through urinary excretion, the increased circulating phosphorus further exacerbates bone turnover. By Stage 4 CKD, it becomes apparent that circulating phosphorus is increasing, and by Stage 5 CKD, serum iP control requires the use of phosphate binder medications in addition to chronic dialysis.

\section{Controlling Serum Phosphorus in ESRD}

Clinicians use a three-pronged approach to controlling serum iP in dialysis patients: (1) removal of ultrafilterable and diffusible phosphorus with dialysis, (2) restriction of dietary phosphate intake, and (3) use of orally administered phosphate binders to limit the absorption from the intestinal contents of ingested phosphate. Despite these efforts, serum iP levels in one-third to one-half of all patients on dialysis run higher than $5.5 \mathrm{mg} / \mathrm{dL}$. While this is often attributed to patient nonadherence, there are a number of legitimate factors contributing to persistent hyperphosphatemia in dialysis patients, including the following:

1. The removal of phosphate during one hemodialysis session amounts to only $800 \mathrm{mg}$ to $1,000 \mathrm{mg}$. Thus dialysis 3 times a week is insufficient to remove the recommended daily intake of phosphorus for patients requiring dialysis $(\leq 1,000 \mathrm{mg} / \mathrm{d})$.

2. It is extremely difficult to limit phosphate intake while attempting to meet the recommended daily protein intake for patients having chronic hemodialysis of 1.1 to $1.3 \mathrm{gm} / \mathrm{kg}$ body weight.

3. Many retail food products have highly bioavailable inorganic phosphate added as a preservative to maintain freshness. As mentioned earlier, these contribute to the patient's phosphate burden.

4. Patients on dialysis have to take multiple medications, and the phosphate binders add to the patient's pill burden.

5. Phosphate binders are generally large pills that are hard to swallow, or if chewed during a meal may distort the sense of taste, making adherence difficult. Furthermore, these medications often cause gastrointestinal upset and are variable in their phosphate-binding capacity.

6. Finally, two additional contributing factors have been highlighted, both related to measures used in the management of these patients. One is the administration of high doses of calcitriol, or its analogues, which are known to enhance active phosphate absorption from the small intestine. The other factor is the lowering of intestinal free phosphate concentration, whether by dietary phosphate restriction or with phosphate binders, which is a known stimulus to enhance phosphate 


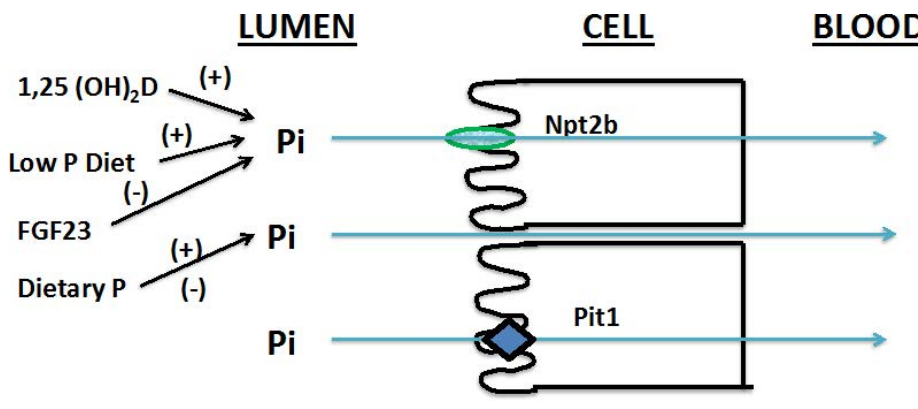

Figure 1. Potential cellular targets for altering phosphate absorption in the small intestine. Sodium-independent phosphate transporter 2b (Npt2b) and Pit 1 are responsible for more than $50 \%$ of phosphate absorption. Pi: inorganic phosphate; FGF23: fibroblast growth factor 23. Reprinted with permission from Weinman et al. ${ }^{6}$

absorption from the small bowel. These two important factors impede the patient's efforts to control their phosphate burden.

All of the above considerations, but especially the last, have led investigators to consider intestinal active phosphate transport as a novel target for therapy. In mice with experimentally induced renal failure and hyperphosphatemia, the hyperphosphatemia was corrected by conditional knockout of the small intestine phosphate transporter, $\mathrm{NaP} 2 \mathrm{~b}$, in combination with sevelamer to reduce passive phosphate absorption (Figure 1). ${ }^{6}$ A novel inhibitor of intestinal $\mathrm{Na} / \mathrm{H}+$ exchange has recently been shown to be effective in controlling hyperphosphatemia in a similar setting. In terms of a clinically available and effective therapy, nicotinamide, a widely used lipid-lowering agent, has been shown to inhibit NaP2b and lower serum iP in CKD patients.

\section{Summary}

The development of more potent inhibitors should be forthcoming, but it is important to emphasize that there will always be a place for phosphate binders to block the passive absorption of phosphate for people with advanced CKD. Furthermore, protecting and monitoring bone health should also aid in controlling serum iP as CKD advances.

\section{Key Points:}

- The kidney, bone, and digestive system elegantly control serum inorganic phosphate (iP), but even people with normal kidney function are known to have a wide range of serum iP, placing them at increased risk for cardiovascular-related mortality.

- Diet, aging, and chronic disease influence the control of serum iP. Low calcium/high phosphorus diets contribute to bone disease. Many people who are age 50 and older have significant osteoporosis and are more prone to cardiovascular and kidney disease.

- Once chronic kidney disease advances to end-stage renal disease, the ability to maintain normal serum iP is drastically reduced with dialysis and phosphorus binding compounds having only limited success in many patients.

- Novel approaches are being explored, such as inhibition of intestinal transport pathways, that may prove beneficial for improving serum iP control and hopefully reduce cardiovascular mortality.

Conflict of Interest Disclosure: The authors have completed and submitted the Methodist DeBakey Cardiovascular Journal Conflict of Interest Statement and none were reported.
Keywords: serum phosphorus, chronic kidney disease, glomerular filtration rate, osteoporosis, phosphates, sodium-phosphate cotransporter proteins, hyperphosphatemia/drug therapy

\section{References}

1. Moore LW, Nolte JV, Gaber AO, Suki WN. Association of dietary phosphate and serum phosphorus concentration by levels of kidney function. Am J Clin Nutr. 2015 Aug;102(2):444-53.

2. Dhingra R, Sullivan LM, Fox CS, et al. Relations of serum phosphorus and calcium levels to the incidence of cardiovascular disease in the community. Arch Intern Med. 2007 May 14;167(9):879-85.

3. Tonelli M, Sacks F, Pfeffer M, Gao Z, Curhan G; Cholesterol and Recurrent Events Trial Investigators. Relation between serum phosphate level and cardiovascular event rate in people with coronary disease. Circulation. 2005 Oct 25;112(17):2627-33.

4. de Boer IH, Rue TC, Kestenbaum B. Serum phosphorus concentrations in the third National Health and Nutrition Examination Survey (NHANES III). Am J Kidney Dis. 2009 Mar;53(3):399-407.

5. Dominguez JR, Kestenbaum B, Chonchol M, et al. Relationships between serum and urine phosphorus with all-cause and cardiovascular mortality: the Osteoporotic Fractures in Men (MrOS) Study. Am J Kidney Dis. 2013 Apr;61(4):555-63.

6. Weinman EJ, Light PD, Suki WN. Gastrointestinal phosphate handling in CKD and its association with cardiovascular disease. Am J Kidney Dis. 2013 Nov;62(5):1006-11.

7. Benjamin RM. Bone health: preventing osteoporosis. Public Health Rep. 2010 May-Jun;125(3):368-70.

8. U.S. Department of Health and Human Services [Internet]. Rockville, MD: U.S. Department of Health and Human Services, Office of the Surgeon General; 2004. Bone health and osteoporosis: a report of the surgeon general; 2004 [cited 2016 Jul 20]. Available from http://www.ncbi.nlm.nih.gov/books/NBK45513.

9. United States Renal Data System [Internet]. Ann Arbor, MI: USRDS Coordinating Center; 2016 [cited 2016 Jul 20]. Available from: http://www.usrds.org.

10. Lemann JJ. Calcium and phosphate metabolism: an overview in health and in calcium stone formers. In: Coe F, Favus M, Pak C, Parks J, Preminger G, editors. Kidney Stones: Medical and Surgical Management. Philadelphia, PA: Lippincott-Raven; 1996: p. 259-288.

11. Cupisti A, Kalantar-Zadeh K. Management of natural and added dietary phosphorus burden in kidney disease. Semin Nephrol. 2013 Mar;33(2):180-90.

12. Bailey RL, Dodd KW, Goldman JA, et al. Estimation of total usual calcium and vitamin D intakes in the United States. J Nutr. 2010 Apr;140(4):817-22.

13. Kemi VE, Karkkainen MU, Lamberg-Allardt CJ. High phosphorus intakes acutely and negatively affect $\mathrm{Ca}$ and bone metabolism in a dose-dependent manner in healthy young females. Br J Nutr. 2006 Sep;96(3):545-52.

14. Kemi VE, Karkkainen MU, Rita HJ, Laaksonen MM, Outila TA, Lamberg-Allardt CJ. Low calcium:phosphorus ratio in habitual diets affects serum parathyroid hormone concentration and calcium metabolism in healthy women with adequate calcium intake. Br J Nutr. 2010 Feb;103(4):561-8.

15. Kemi VE, Rita HJ, Karkkainen MU, et al. Habitual high phosphorus intakes and foods with phosphate additives negatively affect serum parathyroid hormone concentration: a cross-sectional study on healthy premenopausal women. Public Health Nutr. 2009 Oct;12(10):1885-92.

16. Health.gov [Internet]. Rockville, MD: Office of Disease Prevention 
and Health Promotion; 2016 Jul. Dietary Guidelines for Americans 2015-2020, 8th Edition [cited 2016 Jul 22]. Available from: http://health.gov/dietaryguidelines/2015/guidelines.

17. K/DOQI clinical practice guidelines for bone metabolism and disease in chronic kidney disease. Am J Kidney Dis. 2003 Oct;42(4
Suppl 3):S1-S201.

18. Academy of Nutrition and Dietetics [Internet]. Chicago, IL: Academy of Nutrition and Dietetics; 2016. Evidence Analysis Library; 2010 [cited 2016 Jul 21]. Available from: http://www.andeal.org/ topic.cfm?menu=5303. 